Investigaciones Feministas

ISSN-e: 2171-6080

\title{
Mildred Pierce: de la novela a la miniserie. Un personaje femenino relevante y con vigencia en la actualidad
}

\author{
Rocío Gago-Gelado ${ }^{1}$, Mercedes Herrero-de-la-Fuente ${ }^{2}$
}

Recibido: Mayo 2020 / Revisado: Octubre 2020 / Aceptado: Noviembre 2020

Resumen. Introducción. Mediante el análisis de la obra Mildred Pierce en sus tres formatos: novela (1941), película (1945) y serie (2011), nos adentramos en el estudio del personaje protagonista, que tras la crisis de 1929 se separa de su marido iniciando una etapa de independencia profesional y personal, alejada de los cánones que la sociedad de esa época imponía a la mujer. Objetivos. Para ello, entre los objetivos nos planteamos discernir si las características de dicho personaje y los arquetipos en los que podría enmarcarse se ven afectados por el momento en que se realiza cada una de las obras analizadas. Resultados. Para concluir, tal como lo hacen determinadas académicas feministas, la adaptación al cine presenta un enfoque más estereotipado, que parece castigar con su dramático desenlace las aspiraciones de la protagonista. Conclusiones y discusión. Investigamos también el arco de transformación de Mildred Pierce y descubrimos un personaje complejo, vigente en la actualidad, que evoluciona en los tres trabajos considerados y que, basándose fundamentalmente en dos arquetipos («Madre/Reina» y «Creador»), exhibe una personalidad poliédrica, creíble y que permite nuestra empatía. Palabras clave: Mildred Pierce; novela; largometraje; serie; protagonista femenino; vigencia del personaje; evolución del personaje; mujer no convencional; mujer emprendedora; arquetipos.

[en] Mildred Pierce: from the novel to the miniseries. A relevant and valid female character with total relevance today

Abstract. Introduction. By analyzing the work Mildred Pierce in its three formats: novel (1941), film (1945) and series (2011), we entered the study of the main character, who after the crisis of 1929 separated from her husband, initiating a stage of professional and personal independence, far from the standards that society of that time imposed on women. Objectives. To do this, among the objectives we propose to discern whether the characteristics of this character and the archetypes in which he could be framed are affected by the moment in which each of the works analyzed is carried out. Results. To conclude, as certain feminist scholars do, that the adaptation to the cinema presents a more stereotyped approach, which seems to punish with its dramatic outcome the aspirations of the protagonist. Conclusions and discussion. We also investigate the transformation arc of Mildred Pierce and discovered a complex character, currently in force, who evolves in the three works considered and who, fundamentally based on two archetypes ("Mother / Queen" and "Creator"), exhibits a multifaceted personality, credible and that allows our empathy.

Keywords: Mildred Pierce; novel; feature film; TV series; lead female character; character validity; character evolution; non-conventional woman; female entrepreneur; archetypes.

Sumario. 1. Introducción. 2. Marco teórico. 3. Metodología. 4. Mildred Pierce en la novela, el largometraje y la serie. 4.1. Dimensión física. 4.2. Dimensión psicológica. 4.3. Dimensión social. 5. El uso de los arquetipos para la construcción del personaje de Mildred Pierce. 6. Acercamiento al personaje desde épocas diferentes: de los años cuarenta a la actualidad. 7. Evolución del personaje y principales motivaciones. 8. Conclusiones. Referencias Bibliográficas.

Cómo citar: Gago-Gelado, R.; Herrero-de-la-Fuente, M. (2021). Mildred Pierce: de la novela a la miniserie. Un personaje femenino relevante y con vigencia en la actualidad, en Revista de Investigaciones Feministas 12(1), 179-189.

\section{Introducción}

Este trabajo aborda el análisis de un personaje femenino centrándose en su evolución al margen de las convenciones y roles establecidos socialmente para la mujer y a través de tres formatos narratológicos. Mildred

\footnotetext{
mgago@nebrija.es

Universidad Antonio de Nebrija, España

2 mherrero@nebrija.es

Universidad Antonio de Nebrija, España
} 
Pierce es el título de la novela publicada por James M. Cain en 1941, que gozó de gran éxito en Estados Unidos. Cuatro años después dio lugar a la película Alma en suplicio (título con el que se comercializó en España), dirigida por Michael Curtiz y cuya protagonista, Joan Crawford, ganó el Oscar a la mejor actriz principal. La relevancia de esta historia en la actualidad da lugar a una miniserie de cinco capítulos, Mildred Pierce (Todd Haynes, 2011), interpretada por Kate Winslet, que consiguió en HBO una audiencia notable, con 1.300.000 espectadores en su estreno en España (FormulaTV, 2011). Recibió numerosos galardones, entre ellos cinco premios Emmy a la mejor miniserie y el Globo de Oro a la mejor actriz protagonista (Prisa, 2011).

El interés de Mildred Pierce se valida siete décadas después, dentro de una tendencia clara en la producción de series, que apuesta por personajes femeninos muy ricos. Se trata, en la mayoría de los casos, de mujeres con una vida profesional interesante, que toman sus propias decisiones y no se limitan a los papeles que tradicionalmente les adjudica la sociedad. Por mencionar algunos ejemplos podemos remitirnos a las protagonistas de Damages (2007-2012), The Good Wife (2009-2016), Nurse Jackie (2009-2015), The Big C (2010-2012), Girls (2012-2017) o Big Little Lies (2017-2019). Todas ellas series valoradas por los críticos y el público, con intérpretes muy reconocidas, que en algunos casos se implican en otras facetas del proyecto, como la producción ejecutiva (Nicole Kidman y Reese Whiterspoon en Big Little Lies) o son las artífices del mismo (Lena Dunham es la creadora de Girls, además de coproductora ejecutiva y directora y guionista de algunos capítulos).

La trama argumental de la novela Mildred Pierce se sitúa en los años treinta, cuando EE.UU. sufre los efectos del crack de 1929. La protagonista, mujer casada y madre de dos hijas, decide separarse de su marido y asumir la responsabilidad de sostener económicamente a su familia. Y lo hace en un contexto también socialmente desfavorable, en el que se asume que una mujer adulta necesita los ingresos de un marido para sobrevivir.

La esencia de esta historia es recogida en el largometraje y la miniserie. En referencia a la película, es interesante señalar la presión existente en esa época de postguerra sobre los personajes femeninos en las producciones de Hollywood, al entrar en conflicto los distintos discursos que definen la feminidad. Tal como afirman Lloyd y Johnson (2003), ocurrieron transformaciones significativas en la figura del ama de casa durante este periodo y la película de Curtiz (junto a algunas otras de los años cincuenta, como The Three Faces of Eve) muestra: «(...) an important shift in representations of housework, from a form of gendered labour to housewifery as an inflexibly gendered identity» (Lloyd y Johnson, 2003, 8).

La serie también cuestiona los supuestos en cuanto a identidad, género y familia vigentes en la sociedad norteamericana en los años treinta y el periodo de postguerra (Maury, 2017). Es más, a través de sus episodios se plantea una crítica de esas mismas creencias en la actualidad. Para Maury, la obra de Cain se puede concebir como una obra feminista: «Haynes conceives Cain's Mildred Pierce as a (proto) feminist work. Indeed by replicating the novel faithfully, the series brings to light Cain's feminist subtext» (2017, 7). A partir de las tres obras, exploramos el personaje femenino acudiendo a los parámetros propuestos por José P. Pérez (2016), que recogen sus tres dimensiones fundamentales: física, psicológica y social. Abordamos también el estudio de los arquetipos valorando su utilidad para la construcción de personajes.

La mujer representada en Mildred Pierce es el centro de una historia plagada de dificultades. Con el fin de examinar de forma detallada este personaje abordamos el presente artículo con los objetivos señalados a continuación: nos aproximamos a la descripción del personaje de Mildred Pierce para profundizar en él a través de los tres formatos objeto de nuestra investigación (novela, largometraje y miniserie), explorando el comportamiento de la protagonista con respecto a los cánones predeterminados para la mujer en la época, acotados al ámbito doméstico. Discernimos, además, si las características de dicho personaje y los arquetipos en los que podría enmarcarse se ven afectados de forma decisiva por el momento en que se realizan cada una de las obras estudiadas, al ir evolucionando en el tiempo los roles femeninos socialmente aceptados. Por último, analizamos el arco de transformación de Mildred Pierce a lo largo de su historia, para identificar las coincidencias y discrepancias al mostrar su evolución en las tres adaptaciones estudiadas, tratando de averiguar en qué medida cuestionan los conceptos de identidad, género y hogar.

\section{Marco teórico}

En esta investigación observamos el interés narratológico que tiene cada formato. Acudimos a Chatman (1990) y comprobamos que, los procedimientos de narración a los que se refiere el autor, la novela y el cine, son diferentes. El problema al que se enfrentan las adaptaciones es cómo resolver los aspectos propios de la narración literaria, que son difíciles de transferir al cine. Por ejemplo, el hecho de que las películas sean visualmente explícitas no significa que no presentan indeterminaciones tanto a nivel de la historia, como es el caso de las elipsis, como a nivel superficial o estilístico (Chatman, 1990). En nuestro caso de estudio, la adaptación cinematográfica y la televisiva difieren en algunos puntos, como el final y el inicio, que en la película es distinto a los otros dos formatos, pero las tres historias se sostienen sobre los mismos pilares.

Para Rodríguez (2005) la relación del cine con la literatura constituye un debate desde los comienzos del arte cinematográfico. Señala Rifkin (1994) que muchos de los primeros cineastas reconocieron la relación potencial entre las dos expresiones artísticas, cine y novela, buscando obras de literatura como fuentes de guiones 
de cine. Desde la aparición de la industria cinematográfica, el cine se sitúa como un arte de narración de historias y siempre ha existido la tendencia a asociarlo con la literatura, tanto por parte de los cineastas, escritores y críticos, como por parte del público (Beja, 1979). Esta propensión se ha desarrollado igualmente en las series, especialmente en los últimos años, con el aumento de producciones audiovisuales de este género promovidas por distintas plataformas. Por poner solo un ejemplo: su oferta en Netflix se ha triplicado entre 2010 y 2018 (González, 2018). En Mildred Pierce, la adaptación de esta historia de ambición femenina como un cine negro clásico ha inspirado a académicas feministas, que interpretan la película como una reacción a la emancipación temporal de las mujeres en los años de guerra (Maury, 2017).

Lloyd y Johnson (2003) consideran la obra de Curtiz (1945) como un melodrama, que muestra cómo una ama de casa intenta sacar a flote un hogar con un marido ausente. El largometraje explora de qué manera las mujeres de esa época podían tratar con el mundo moderno, manteniendo al mismo tiempo la imagen de la feminidad doméstica. Estas autoras añaden:

These women use their experiences in the private sphere to their advantage in the public sphere, becoming waitresses or restaurant and service industry entrepreneurs. They negotiate the damning diagnosis of being "just a housewife," as an employment agent describes Mildred Pierce, explaining why she is only offered demeaning jobs as a domestic worker when she looks for work after her husband leaves (...) (Lloyd \& Johnson, 2003, 14).

El formato miniserie permite contar con más detalle la historia de Mildred Pierce. Apreciamos en este caso mayor desarrollo en la trama que en la película, ya que las series dramáticas integran verdaderos discursos de realidad y están formadas por pequeños fragmentos que pretenden constituirse como un espejo, transmitiendo modelos de conducta, prejuicios, valores y comportamientos sociales (Galán, 2006). La protagonista intenta superar las adversidades y lo hace con comportamientos y actitudes que escapan a los cánones impuestos por la sociedad de esa época para la mujer. Concluye Maury (2017) que Mildred Pierce es claramente una alegoría de la mujer estadounidense, manejando variables como la invisibilidad, la maternidad y la emancipación financiera a través del trabajo. La protagonista se pone a prueba e intenta superar las adversidades que la vida le plantea. En este punto acudimos a la teoría principal de Simone de Beauvoir, que sostiene que "la mujer", o lo que entendemos por mujer (coqueta, frívola, caprichosa, salvaje o sumisa, obediente, cariñosa, etc.), es un producto cultural construido socialmente, que a lo largo de la historia se ha definido siempre respecto a algo: como madre, esposa, hija, hermana... Refiriéndose a estas palabras, recoge Herrero (2010) que la principal tarea de la mujer es reconquistar su propia identidad específica y desde sus propios criterios. En las tres creaciones analizadas se refleja un personaje femenino, que rompe con los patrones encarnados mayoritariamente por las mujeres de esa época.

Una historia que empatice con el espectador ofrece la oportunidad de trasladarnos a una vida diferente, porque la trama argumental necesita acciones y personajes que la lideren (Navarrete-Galiano, 2012). Mildred Pierce, en cada uno de los formatos, nos acerca a distintos matices puesto que, como asegura Pérez, «el estudio del personaje cinematográfico posibilita el logro de un amplio número de conclusiones acerca de la construcción del discurso fílmico» $(2016,535)$. A través de los personajes accedemos a interpretaciones del mensaje que no siempre son muy evidentes, o contrastamos el distinto modo en que han sido concebidos determinados modelos o tipos de caracteres en diversas prácticas cinematográficas, ya sea de momentos diferentes en la historia del cine o de prácticas nacionales específicas (Pérez, 2016). Incluiremos todo ello en este estudio, centrado en tres creaciones que giran alrededor de un mismo personaje, pero se desarrollan separadas en el tiempo. En este sentido, Grossman (2009) señala que la película de Curtiz es un ejemplo de cómo en ocasiones la promoción, la publicidad y la crítica cinematográfica pretenden reformular el personaje femenino como el malo (la mala, en este caso) de la película.

Atendiendo a los objetivos propuestos nos centramos en la historia de Mildred Pierce, una mujer separada en la California de los años treinta, que lucha por sacar adelante a sus hijas creando su propio negocio. Este autor (2016) presenta una vía en la que considera al personaje como unidad psicológica y de acción, entendiéndolo como un agente de la trama, pero construido como si se tratara de una entidad con una psicología propia. De aquí surge nuestra metodología de análisis donde se incluye el estudio de tres dimensiones: física, psíquica y social. Los análisis formales, es decir, del personaje como rol, posibilitan el reconocimiento de su función y actividad, o de sus posiciones morales, positiva, como la del héroe, o negativa, como la del antagonista. Pero más allá de esta identificación y categorización nos permitirán la obtención de conclusiones más profundas. Vamos a primar, por tanto, una visión del personaje como persona, tomando un enfoque más fenomenológico que formal o estructural. De este modo, partimos de una convención admitida por los agentes de la comunicación, es decir, podemos analizarlo psicológicamente, pero debemos recordar que hablamos de personajes y no de personas (Chatman, 1990).

Para conformar una historia creíble que atrape al espectador, los personajes deben ser coherentes con su perfil, lo que no significa, apunta Zamarripa (2006), que sean previsibles. Para este autor quizá sea la parte más difícil en la creación de personajes multidimensionales y realistas. La coherencia tiene que ver con los valores éticos, puesto que el escritor a través de los valores puede mostrar su punto de vista (Seger, 2000). Para McKee (2004), una buena historia debe ser universal y arquetípica, por oposición 
a las historias estereotipadas. Ha de desvelar una experiencia humana extrapolable, aunque vestida de una expresión única y una cultura específica. Este autor apuesta por la construcción de un arquetipo con entornos y personajes poco comunes, en cuyos conflictos hallemos nuestra propia humanidad. Mildred Pierce cumple con estos requisitos y representa a la clase media de mujeres americanas, porque los personajes de Cain poseen esa dimensión universal (Maury, 2017). David Madden y Kristopher Mecholski (2011) han puesto de manifiesto que este escritor narró historias en las que se evidencian los rasgos más característicos de la sociedad estadounidense, incluyendo la búsqueda del éxito como leitmotiv esencial y las desastrosas consecuencias que ello puede tener.

Es importante que una obra artística consiga que el espectador se identifique con los personajes a través de sus acciones y decisiones y para lograrlo el autor debe contextualizar la sociedad en la que transcurre el argumento y plantear conflictos interesantes: «La identificación con los personajes es un mecanismo a través del cual los sujetos experimentan e interpretan una narración desde dentro, como si los acontecimientos que se relatan les estuviesen ocurriendo a ellos mismos» (Igartua, 2008, 43). Con esta finalidad hablamos de los arquetipos, cuyo objetivo, como indican Atarama, Castañeda y Agapito (2011), es trasladar al espectador a un mundo ficticio extraño y exótico, no para huir, sino para que, a través de la belleza de la obra, pueda encontrarse realmente consigo mismo (Mckee, 2008). Estos patrones psicológicos enriquecen el universo en el que conviven aportando verosimilitud: «Un relato con personajes arquetípicos supera las barreras de los países, las culturas y las clases sociales, viajando en un mundo globalizado, por lo que es importante familiarizarse con los arquetipos para crear un relato verdaderamente relevante y significativo para millones de espectadores» (Núñez, 2007: 167).

Según afirma León del Río (2009), Jung encontró arquetipos relacionados con la totalidad o con el símismo, a través de los sueños, las visiones y, en segundo término, los productos de la imaginación activa. Estos arquetipos nacen de la unión de las cuatro funciones del ser humano (dos racionales, la inteligencia y la sensibilidad, y dos irracionales, la percepción y la intuición) con los temperamentos hipocráticos, quienes aportan conocimientos necesarios para la construcción de personajes y sus arcos de transformación (Atarama, Castañeda y Agapito, 2011). Recogen estos autores que lo que atrapa y afecta al espectador es el universo del argumento, compuesto por una red compleja y detallada de elementos significativos para el guion, de los cuales el más importante es la red de personajes y, en particular, del protagonista (Truby, 2009). Este, después de pasar por etapas y obstáculos en su vida, vive una transformación, logre o no su objetivo, que nutre su crecimiento personal humanizando su personaje, adquiriendo las cualidades necesarias para actuar de manera convincente y así hacer de la acción diegética una actuación verosímil (Caman y Atarama, 2015). Comprobaremos si (o cómo) Mildred Pierce cumple estos requisitos, demostrando la forma en que deja entrever, sin pretenderlo, la fortaleza de una mujer cuyas acciones se alejan de lo convencional en esa época.

\section{Metodología}

Para la elaboración de esta investigación partimos de un corpus integrado por las tres obras mencionadas. Hemos manejado una edición en español de 1980 (365 páginas) en el caso de la novela y hemos visionado el largometraje (109 minutos) y los cinco capítulos de la serie (en torno a sesenta minutos de duración cada uno), ambos en versión original con subtítulos. Nuestra investigación se detiene en la representación de la mujer en las tres adaptaciones objeto de estudio.

Abordamos el análisis del personaje basándonos en los parámetros propuestos por José P. Pérez (2016), que recogen sus tres dimensiones fundamentales: física, psicológica y social. Cada una de ellas se divide en distintos apartados que permiten ahondar de forma detallada en Mildred Pierce. En la dimensión física incluimos: edad, fisonomía, vestuario, gesto y expresión verbal. La psicológica engloba lo relativo a carácter, desglosado en decisiones, acciones y motivaciones. En la dimensión social nos referimos a lo que concierne a vida profesional, vida privada y pasado de la protagonista. Los mencionados parámetros nos conducen a los arquetipos utilizados para la construcción del personaje. Determinamos qué componentes de estos arquetipos predominan en cada una de las obras manejadas, indagando sobre si estos convergen, difieren o son complementarios y reflexionando sobre su relación con los papeles que la sociedad impone a la mujer en cada época.

Se trata de un enfoque cualitativo, que indaga en las características de Mildred Pierce y en su tratamiento en la novela, el largometraje y la miniserie aplicando los métodos descriptivo, analítico y comparativo.

Hemos fundamentado nuestro trabajo en una revisión bibliográfica, centrada básicamente en: la representación del papel social de la mujer en obras de diferentes épocas, con especial atención a la tensión entre las aspiraciones femeninas y los esquemas tradicionales preestablecidos; las adaptaciones necesarias para trasladar una obra literaria a otros formatos; las distintas metodologías de análisis de los personajes; por último, el uso de arquetipos para su construcción dentro de un relato coherente, aspecto en el que ponemos una parte importante del foco de nuestro estudio. 


\section{Mildred Pierce en la novela, el largometraje y la serie}

Descubrimos, al explorar a Mildred Pierce, a un personaje redondo, complejo, lleno de matices, inspirador en muchos momentos, pero no carente de contradicciones. A lo largo de las tres versiones analizadas, se mantienen una serie de rasgos principales, pero al mismo tiempo se observan algunas diferencias que vienen dadas por el énfasis en uno u otro aspecto que estudiaremos para analizar el personaje en función de su desempeño dentro y fuera del espacio doméstico.

\subsection{Dimensión física}

Nos detendremos, a continuación, en los aspectos físicos que definen a la protagonista recopilando las diferencias y semejanzas más significativas existentes entre la película, la miniserie y la novela:

- Mujer joven, cuya historia se nos presenta cuando tiene 28 años y cría a dos hijas (la mayor, Veda, de 11 años). Al final del relato ha cumplido 37.

- Físicamente es atractiva, no muy alta, con un cuerpo voluptuoso y está muy orgullosa de sus piernas, rasgo en el que se incide en numerosas ocasiones. Su pelo es rubio parduzco, sus ojos azules y muy expresivos. Posee una risa encantadora y es definida por Cain como alguien que llama la atención. Esta apariencia física se mantiene con bastante fidelidad en la miniserie, si bien la actriz Kate Winslet es tal vez un poco más corpulenta de lo descrito. En la película, en cambio, la fisonomía de Joan Cradford se ajusta menos a estos patrones, al aparecer con el pelo oscuro y mostrar su rostro con cierta dureza. Por otro lado, rodó esta producción con 41 años.

- Mildred es coqueta e intenta que su aspecto sea siempre el adecuado. En los primeros años, después de la separación, posee un vestuario muy limitado. Aun así, aparece arreglada, sobre todo cuando sale a buscar trabajo, y aunque esté haciendo tartas presenta un aspecto agradable. Cuando gana dinero su apariencia es más sofisticada, pero no es presentada como esclava de su imagen. La caracterización en la serie respeta lo establecido en la novela. La película también lo hace, pero incide en la elegancia de la protagonista. Dedica más minutaje a los años de prosperidad que a los de escasez, por lo que exhibe sombreros, guantes y abrigos de piel, pero con un estilo sobrio.

- No es excesivamente expresiva. Su gestualidad es bastante medida, tanto en lo facial como en lo corporal. Este aspecto se aprecia con mucha más precisión en las dos producciones audiovisuales, que muestran diferencias entre sí. El largometraje nos presenta a una mujer con gran autocontrol que afronta con entereza los momentos de crisis. La aproximación al personaje de Kate Winslet es tal vez más humana, deja ver de forma más explícita la decepción, el abatimiento, la ternura, o el enfado.

\subsection{Dimensión psicológica}

Sobre su personalidad, detectamos las siguientes características que se extraen de sus decisiones y acciones, así como de las motivaciones que la impulsan:

- Es hábil e inteligente. Es muy buena cocinera y esto la conduce al éxito en los negocios. En numerosas ocasiones aparece en la cocina, rodeada de tartas. Hay una frase de la protagonista en el minuto 21'03' del largometraje, cuando habla de sí misma ante la policía, que resume el peso que esto tiene en su día a día: "Yo estaba siempre en la cocina. Me parecía que había nacido en la cocina y pasado allí toda mi vida... Y había salido solo unas horas para casarme". En la novela el hecho de saber cocinar se expone al principio como una manera de demostrar que una mujer puede ser una buena esposa. Pero Mildred trasciende esta creencia y utiliza sus dotes gastronómicas no para conseguir un nuevo marido, sino para labrarse un futuro.

- Activa y trabajadora. Apenas la vemos descansando, siempre está trabajando, primero cocinando o como camarera y después organizando sus restaurantes, cuentas, etc.

- Emprendedora. Es uno de sus rasgos fundamentales. Ya lo demuestra cuando hace tartas por encargo y progresa hasta abrir su primer restaurante, sin experiencia y sin recursos económicos. Tiene olfato para ver las oportunidades de negocio (abre un establecimiento donde solo se sirve pollo con el fin de evitar las pérdidas que supone desechar comida cuando se ofrece un menú muy amplio). En poco tiempo inauguró dos establecimientos más. En la novela todas sus elucubraciones sobre cómo hacer funcionar un restaurante, cuál sería su ubicación ideal, etc. son contadas con bastante detalle. La película da menos importancia a esta fase y, seguramente por disponer de menos tiempo, simplifica este proceso lleno de dudas y miedos, que sí se refleja en la miniserie.

- Toma las riendas de las situaciones. Detesta la pasividad y siempre asume sus responsabilidades. Esta es una de las razones por las que se separa de su primer marido. Es ella quien encuentra la forma de saldar sus deudas. 
- Posee sentido práctico, puede ser muy calculadora en determinadas situaciones. Esto se ilustra al principio con pequeños detalles, como intentar, cuando recibe una visita en casa (en los momentos de apuros económicos), que su invitado se vaya antes para no empezar una botella de whisky que puede revender a buen precio: «Pensó que, si lograba no tener que abrir la botella de whisky, podría venderlo y ganar 6 dolares», (Cain, 1980, 48). Sus cálculos van más allá de sus negocios y se centran a partir de determinado momento en su relación con Monty y, sobre todo, en la vida de su hija Veda. Este carácter manipulador se refleja de forma más clara en el largometraje. La serie muestra a una Mildred más movida por sus sentimientos que por sus cálculos, cegada por la pasión que siente por su hija, más que actuando para su propio beneficio.

- Tiene complejo por no ser una persona instruida. Por eso siente debilidad por Monty y por Veda. Sin ser soberbia, ese complejo le lleva a veces a mostrarse presuntuosa. Aunque no ha estudiado posee una gran capacidad de aprender. Sobre este conflicto se ahonda en la novela, que es probablemente la que profundiza más en las contradicciones del personaje. También la miniserie muestra sus inseguridades y cómo se esfuerza por superarlas.

- No quiere asumir el papel de tonta frente a los hombres, aunque es consciente de que, en muchos casos, en una sociedad machista, es la manera más sencilla de conseguir lo que necesita. En el libro, el autor nos muestra a Mildred reflexionando sobre esto: no acepta los consejos de buscarse un marido que la mantenga y recibe mal cómo la tratan los hombres cuando es camarera. Sin embargo, a veces sucumbe ante este esquema y pide a su marido que le deje la casa para vivir con sus hijas, sin mencionar que por derecho le corresponde parte de esta propiedad, porque también ella ha sufragado la hipoteca. Este matiz se explica en la novela, pero la película y la serie apenas se detienen en él.

- Independiente y con cierto punto de orgullo. No pide ayuda a su familia cuando se separa de Bert e intenta salir adelante sola. Obligada por la necesidad económica acepta ser camarera. Antes había rechazado otras ofertas que consideraba indignas para sus hijas (en especial para Veda), como ser ama de llaves. El periodo en que busca empleo sin ningún éxito es relatado de forma extensa por Cain, mostrando su abatimiento y preocupación. También la miniserie dedica bastante tiempo a esta fase, al contrario que la película.

En sus relaciones sentimentales, estas características no se dibujan tan claramente. Se aprecian al no consentir la infidelidad de su marido, a pesar de que ello implica separarse. Pero en relación a su amante, Monty, solo después de sufrir grandes decepciones es capaz de afrontar una ruptura. La novela relata con detalle las numerosas ocasiones en que él la utiliza para financiar sus caprichos.

El mismo proceso y con una dependencia mucho mayor se desarrolla con Veda, por la que siente una adoración que roza lo malsano. Mendiga su cariño y en algunos puntos lograr su aceptación define todas sus acciones, llevándola a tomar decisiones equivocadas. Ante ella siempre claudica, pierde toda su confianza y fortaleza, se siente insegura e inferior. Esta obsesión se observa en momentos de la novela, por ejemplo, cuando muere su hija menor y esa misma noche Mildred va a la cama donde duerme Veda y la abraza largamente. El narrador describe así este momento: «Entonces se deshizo en un torrente de lágrimas entrecortadas, cediendo finalmente a la cosa contra la que había luchado hasta entonces, a la secreta y regocijada alegría de que se hubieran llevado a la otra niña, en lugar de Veda» (Cain, 1980, 165). Se trata de una escena chocante que se reproduce bastante fielmente en la serie, al final del capítulo dos, donde no existe la voz del narrador, pero la protagonista da gracias a Dios mientras aprieta su cuerpo contra el de su hija. No se incluye en el largometraje.

- Sincera y en general honesta. Suele decir lo que piensa, así lo hace cuando prácticamente echa a su primer marido de casa porque tiene una amante. Es objetiva cuando habla de su separación, no se presenta como una víctima, reconociendo que el matrimonio no funcionaba tampoco para ella. Cuando su suegra culpa a la amante de Bert de lo ocurrido, Mildred expresa su indignación, no acepta que la mujer no apele a la responsabilidad de su hijo. También es muy franca en una de sus primeras conversaciones con Wally, antiguo socio de su marido, al que acusa de haberle engañado. Esta dureza no se recoge en la película, pero sí en el texto literario y en la miniserie. Igualmente es muy realista en su relación con Monty. No se engaña, es consciente del provecho que saca de ella y se lo reprocha en varias ocasiones.

- Tiene una forma de expresarse directa y no duda en manifestar sus opiniones. Esto no es un rasgo predominante en las mujeres de su época, a las que se invita siempre a ser amables y comedidas, especialmente en sus relaciones con los hombres. Con sus hijas, especialmente con Veda, es dulce, salvo en los momentos puntuales en que se enfrenta a ella. Su forma de comunicarse es de nuevo más contenida en la película, incluso en las escenas dramáticas, tal vez condicionado esto por la interpretación de Joan Crawford.

- Fuerte, supera las situaciones adversas. La muerte de su hija menor es uno de los giros más dramáticos, aunque en el largometraje tiene menos peso que en los otros dos formatos. Ella lo afronta con el coraje que la caracteriza, autorizando pagar una transfusión cuyos gastos apenas podría sufragar, y con entereza, cuando se produce el fatal desenlace. Este hecho sirve para reafirmarse en su existencia 
como mujer libre, más allá de su papel de madre, ya que la niña enferma cuando pasa un fin de semana con sus abuelos, momento en el que Mildred, de forma imprevista, conoce a Monty y se va con él dos días a la playa. Esto hace que no esté localizable en las primeras horas en que su marido intenta comunicarle lo que ocurre. Cuando finalmente se reúne con el resto de su familia la pregunta de todos, especialmente de su suegra, es por qué no estaba en casa. Nuestra protagonista se defiende ante los reproches y no pide disculpas por no permanecer en su hogar esperando a sus hijas.

No es rencorosa. A pesar de lo sucedido con su primer marido no guarda resentimiento. Intenta ayudarle y se convierte en un amigo con quien habla de lo que le preocupa. Jamás busca su descrédito ante las personas que le conocen y mucho menos ante sus hijas. Tampoco siente rencor por Monty y solo cuando la coloca en una posición insostenible acaba del todo con él. Con respecto a su ruptura final con Veda, parece ante todo sentir dolor. La novela llega a simplificar un tanto este estado de ánimo y la hace pasar de un total abatimiento a un momento en el que bromea con Bert y repite su frase «Al cuerno con ella» (Cain, 1980, 365), para expresar que sus desvelos han terminado. Ese proceso es más complejo en la serie. Se le dedica una larga escena con la que concluye el último capítulo y, aunque acaba diciendo lo mismo, la actriz es capaz de expresar su pesar y lo confundida que se siente. En la película esta escena no se recoge, ya que el desenlace de la historia es otro.

\subsection{Dimensión social}

Una vez definidas las principales características de la personalidad de Mildred Pierce nos detenemos brevemente en su dimensión social. Su vida personal, como observamos, no está libre de conflictos e influye directamente en este apartado. En este ámbito se proyecta la suma de las dimensiones anteriores:

Es una mujer separada, que tiene que sostener a sus hijas en un contexto de crisis económica. No recibe apoyo de su familia, con la que apenas se relaciona, ni siquiera cuando sufre la muerte de Ray, la menor. Después de un romance pasa por un segundo matrimonio y un segundo divorcio para terminar la historia casándose con su primer marido. Su hija Veda es quien la impulsa un tanto por accidente a progresar profesionalmente, ya que cuando descubre que trabaja como camarera, Mildred le dice que solo lo hace para aprender cómo funciona un restaurante y abrir el suyo propio, en una escena que es calcada en los tres formatos. Con ello trata de evitar el menosprecio de Veda y se ve obligada a abordar este proyecto. De esta forma pasa de ama de casa a camarera y rápidamente a empresaria, para convertirse en toda una mujer de negocios, dedicada y responsable.

A pesar de su posición económica, no está integrada en las esferas de la alta sociedad, pues no pertenece a los círculos de personas nacidas ya en un entorno privilegiado. Es este hecho, el de pertenecer a la burguesía, uno de los rasgos que más le llama la atención de Monty. También admira de su hija Veda su capacidad para desenvolverse en esos ámbitos. Mildred es una mujer que se ha construido a sí misma, sin embargo, su origen humilde provoca el desprecio de su hija Veda.

\section{El uso de los arquetipos para la construcción del personaje de Mildred Pierce}

Partiendo de los arquetipos psicológicos de Jung (1988) y en las clasificaciones posteriores de Núñez (2007) y Truby (2009), la investigación de Atarama, Castañeda y Agapito propone una serie de arquetipos adaptados al guion con diversas categorías, dos de ellas idóneas para la definición de Mildred Pierce. Se trata de «Madre/ Reina» y «Creador» $(2011,7)$. La primera se caracteriza por ser sabia, protectora y empática, pero como contrapartida también tiende a la sobreprotección y el control. El segundo arquetipo define una parte esencial de nuestra protagonista, al ser perseverante, perfeccionista y con miedo a no tener el talento necesario.

Dentro del arquetipo «Madre/Reina» las motivaciones de nuestro personaje son nobles, cuidar y mantener a sus hijas después de la separación de Bert y, posteriormente, gracias a su trabajo y agudeza para los negocios, obtener unos beneficios económicos que emplea en construir un mundo de ensueño para Veda, a la que rodea de todo tipo de lujos y proporciona la formación que ella nunca ha tenido. Pero en ese intento de ganarse la admiración de su hija, que nunca agradecerá sus esfuerzos, traspasa determinados límites que convierten su abnegación en manipulación. Detectamos lo anterior cuando aparta a Monty de su vida porque cree que es una mala influencia para Veda. Poco después, cuando tras una gran bronca la expulsa de su casa y no ve manera de recuperarla, se reconcilia con su amante y le propone matrimonio, a pesar de no estar ya enamorada de él. De esta manera, planea recuperar a su hija, que nunca ha ocultado su atracción por el mundo sofisticado que representa Monty. Su faceta calculadora llega en esta serie de acciones a su máxima expresión, mostrando un afán de control y una desesperación, al mismo tiempo, por mantener cerca a Veda.

Mildred Pierce encaja también en el arquetipo «Creador», ya que persiste con gran empeño en lograr aquello que quiere, pero a la vez siente cierta inseguridad por su falta de preparación. En su búsqueda de un trabajo con el que poder subsistir y ante la posibilidad de ser camarera, ensaya en su casa cómo llevar los platos (esta 
es una escena que se repite en las tres obras analizadas). Cuando ya lo ha conseguido quiere ascender y decide hacer tartas para el café donde está empleada, lo que implica trabajar día y noche hasta conseguir un reconocimiento por parte de sus compradores. En esta capacidad de trabajo y sacrificio se incide mucho, tanto en la novela como en las dos adaptaciones audiovisuales. Su siguiente objetivo es montar un restaurante, al que le siguen dos más. La exigencia consigo misma es un tanto excesiva, matiz que nos indica que tiene miedo a fallar, a no saber mantener sus negocios y volver al punto de partida. Este rasgo se acentúa con su afán de alimentar la burbuja en la que pretende mantener a Veda, que, por otro lado, consigue con sus desprecios ahondar en las inseguridades de su madre. Busca su humillación al reprocharle, por ejemplo, que su trabajo en la cocina la impregna de un olor permanente a pollo frito y se distancia así del origen social humilde de su progenitora. La humillación que sufre por ello nuestra protagonista es reflejada con detalle, sobre todo en la novela y la serie.

\section{Acercamiento al personaje desde épocas diferentes: de los años cuarenta a la actualidad}

Con los mencionados arquetipos se puede definir a una mujer con cualidades y defectos, se construye un personaje creíble, que actúa con coherencia y, sobre todo, vigente tanto en los años cuarenta como en la actualidad. Lo anterior no impide que la manera de abordar determinadas cuestiones varíe en las tres obras manejadas, de forma que encontramos algunos matices que exponemos de forma sucinta. Se relacionan con tres aspectos de los arquetipos aludidos:

- El largometraje incide más en el lado frío, calculador y controlador, es decir, en la parte negativa de los arquetipos mencionados. Desde el momento en que ejerce de empresaria, Mildred toma decisiones muy pensadas, que afectan a su vida personal y a sus negocios. Esto conecta con la tendencia antes mencionada en las producciones norteamericanas de posguerra, en las que una mujer encarna a un personaje malvado (o que tiene algo de ello).

- La novela y la miniserie se extienden más en cómo Mildred vive su sexualidad. Determinados elementos de la narración relativos a esta faceta son eliminados en la película, cuyo enfoque resulta más conservador. En ella el componente sexual de su relación con Wally es obviado, de forma que, aunque este se la insinúa, nunca pasan de ser amigos. Tampoco el romance con Monty es desarrollado de la misma forma que en los otros dos formatos, donde se profundiza en la fuerte atracción física que ejerce sobre nuestra protagonista. Esta pasión termina agotándose, pero renace puntualmente, aun cuando ya no se siente enamorada de él. En general todas las escenas de contenido sexual son eliminadas en la versión cinematográfica. En concreto, el momento en que Mildred sorprende a su hija con Monty en la propia cama del matrimonio, es transformado en un simple beso que se produce en la casa de la playa.

Si bien este barniz puritano se explica por la época en que se estrena el largometraje, llama la atención que la obra literaria, publicada cuatro años antes, aborde estos contenidos con mucha más libertad. Al hacerlo nos ofrece un personaje más humano, que no se ciñe a las convenciones sociales y se rige por la necesidad de ser independiente. Con esta dimensión de mujer que no renuncia a su lado sexual, se añade un componente que da complejidad al personaje, sin dejar de presentar los atributos del arquetipo «Madre/Reina» (los recordamos: protectora, sabia, empática).

- Igualmente la obra cinematográfica se diferencia de las otras dos en que explota más el lado dramático de la historia. Toda la trama gira en torno al asesinato de Monty: la película parte de este momento y la declaración de la protagonista en la policía sirve de herramienta para ir contando toda su historia. Este desenlace se produce cuando Veda, tras ser sorprendida con Monty, asegura a su madre que van a casarse, pero el hombre la reprende y afirma no tener intención de dejar su actual matrimonio. La joven lo mata de un disparo y Mildred encubre su delito. Es más, conduce al lugar del crimen a Wally, al que intenta hacer parecer culpable. Este giro de la historia incide en el carácter protector del personaje, pero también en su lado manipulador, ambos correspondientes al arquetipo «Madre/Reina».

Se puede concluir que la novela y la serie abordan a nuestra protagonista con mayor profundidad, en parte por disponer de una extensión mayor para contar la historia, presentando a una mujer con sus contradicciones, fuerte y liberada en algunas situaciones, y vulnerable también, como recoge el arquetipo de «Creador», en especial frente a Veda.

\section{Evolución del personaje y principales motivaciones}

Uno de los aspectos más relevantes de Mildred Pierce es su evolución a lo largo de la historia y su capacidad para afrontar las dificultades que se le presentan para las que, en la mayoría de los casos, no está preparada. 
Esto sucede tanto en la dimensión social como en la personal. Las tres obras analizadas presentan claramente este proceso, con más detalle en el caso de la novela y la miniserie. El largometraje pasa de unas situaciones a otras sin explicar determinadas cuestiones que sí se recogen en los otros dos formatos. La principal transformación a la que asistimos es la del ama de casa que se convierte en empresaria. Su motivación es encontrar un modo de vida para su familia, pero más allá de eso subyace un afán de superación y una ambición profesional. En líneas generales asistimos a un cambio esencial, en el que una joven con muy poca experiencia conquista una posición económica y social. La película hace especialmente hincapié en esta faceta. Pero su éxito en los negocios forma parte de su crecimiento personal.

Sin embargo, una serie de gastos exagerados en su afán de retener a Veda la llevan a grandes pérdidas económicas. De ser sensata y organizada pasa a realizar operaciones contables por las que finalmente pierde su mansión y dos de sus establecimientos. La empresaria ejemplar se diluye aquí frente a la madre desesperada por obtener el reconocimiento de su hija.

Pero esta motivación, fundamental en todas las decisiones y acciones de nuestra protagonista, también cambia. Comprobar que su segundo marido le es infiel con Veda acaba por romper con esa dependencia emocional enfermiza. Después de años de idolatrarla, concluye que es mejor que permanezca fuera de su vida. De este modo termina una evolución llena de altibajos, ya que la adoración obsesiva hacia ella hacía que la perdonara siempre. La película no deja tan claro este punto, puesto que hasta el final Mildred la defiende e intenta encubrirla frente a la policía. Pero en los otros dos formatos sí hay una escena, en la misma habitación en que ha sorprendido a los amantes, en la que nuestra protagonista se sume en una total desolación, e inmediatamente después el final de la novela y el de la miniserie revelan esa ruptura.

También sus sentimientos hacia Monty se transforman y de la pasión inicial transita al reproche y el cinismo. Enseguida es consciente de que él la utiliza, tal como expresa Cain: «A ella comenzó a atormentarla la sospecha de que él la tomaba por una mera criadita, bastante divertida, con bonitas piernas y una halagüeña conducta en la cama, pero nada más que una criada» $(1980,188)$. Hay también un diálogo que se recoge en la película en el que Mildred afirma: «Me desprecias porque trabajo para vivir. Vendo lo que cocino y hago dinero, que tú compartes [...] No rechazas los billetes con olor a grasa», $\left(1.14{ }^{\prime} 40^{\prime \prime}-1.15{ }^{\prime} 21\right)$. Ocurrido esto, decide romper con él, pero lo recupera cuando cree que le conviene para provocar la vuelta a casa de Veda. Cuando le propone matrimonio llega al punto de sentenciar «Vendido» (1.36'00").

Es llamativo que, tras años de metamorfosis, Mildred llega a una situación muy próxima al punto de partida de su historia. El afecto que profesa a su primer marido culmina en un reencuentro de la pareja, que se casa de nuevo, volviendo a su primera casa y con el reto de hacer funcionar su primer restaurante. Se trata de un final inesperado, que se introduce de forma un tanto abrupta en la narración, especialmente en la novela (no se incluye en la película) y que plantea algunos interrogantes sobre la evolución del personaje. Lo que en un primer momento puede parecer un paso atrás, se interpreta finalmente como un mensaje de liberación: Mildred Pierce acaba con su principal esclavitud y afronta su vida superando la necesidad de reconocimiento por parte de Veda.

\section{Conclusiones}

Mildred Pierce constituye un personaje poliédrico, descrito con mucho detalle en las tres obras analizadas. La novela, la película y la serie nos muestran a una mujer independiente, no sujeta a las convenciones de su época ni en lo personal ni en lo laboral, con grandes cualidades humanas y profesionales, pero también con debilidades y contradicciones. La fortaleza de nuestra protagonista se refleja en su capacidad para acabar con un matrimonio que no le satisface o para dirigir un negocio sin contar con medios ni preparación para ello, pero se desvanece en su relación con su hija Veda. Frente a ella se siente una mujer vulgar e insegura, dentro de una relación determinada por la dependencia emocional, en la que la madre mendiga continuamente el afecto y el reconocimiento de una hija manipuladora, soberbia e ingrata. Después de abordar el análisis de las dimensiones física, psíquica y social, concluimos que Mildred Pierce es un personaje femenino muy rico, lleno de aristas, siendo el largometraje el que menos profundiza en determinados aspectos, al estar condicionado por una duración más breve.

En este artículo hemos reflexionado de forma expresa sobre la capacidad de esta mujer para huir de las convenciones y ejercer un papel que la sociedad de su época le niega. Ante un momento de grandes dificultades económicas, opta por desarrollar un negocio y obtener por sí misma sus ingresos. Sus cualidades como cocinera se convierten en un factor clave, sacándola del confinamiento de su cocina y permitiéndole, de este modo, un desarrollo en la esfera privada y en la pública. Su decisión de separarse de su primer marido la distingue también, no solo por su valentía e independencia, sino por su determinación de existir fuera de la etiqueta de esposa, cuestionando así el comportamiento general de las mujeres de los años treinta en EE.UU. Por último, su relación con su amante muestra un componente de libertad, que raramente es tratado en las novelas de los años cuarenta y que, de hecho, se invisibiliza en la adaptación que hace Hollywood de esta historia en el periodo de postguerra. 
Nuestra investigación observa la utilidad de los arquetipos en la construcción de personajes y, siguiendo la estela de estudios anteriores, hemos asociado Mildred Pierce en función de sus principales características con dos de ellos, denominados "Reina" y "Creador". Existen múltiples ejemplos a lo largo de la historia tratada que obedecen al esquema de persona sabia, protectora y empática, pero a la vez controladora, que definen al primer arquetipo. Todos estos rasgos los encontramos sobre todo en el terreno personal y en su forma de relacionarse con su hija Veda. Al mismo tiempo, el segundo arquetipo se revela en su carácter perseverante y perfeccionista, cualidades que aplica en el desempeño de sus negocios, pero afectado al mismo tiempo por un temor continuo de no contar con talento suficiente para ser empresaria. El arquetipo "Creador" se centra en mayor medida en su entorno laboral, pero afecta también a la relación materno-filial. Siguiendo estos dos modelos se define una mujer con cualidades y defectos, que constituye un personaje creíble, el cual actúa con coherencia, a pesar de algunas paradojas.

Las tres narrativas analizadas nos muestran este resultado, si bien en el largometraje se incide más en el carácter calculador y se fomenta el dramatismo en algunos puntos de la historia (haciendo girar su trama en torno al asesinato de uno de los personajes). En el formato cinematográfico se obvia el lado sexual de nuestra protagonista que está reflejado en la relación con su amante en la novela y, más aún, en la serie. Por tanto, los arquetipos mencionados constituyen un engranaje muy eficiente. Como queda señalado en nuestro análisis, no se desarrollan en todas las obras de la misma forma, incidiendo en cada una de las adaptaciones tratadas en determinados aspectos de cada arquetipo. Esto nos sugiere un uso complementario de las distintas capas que integran "Reina" y "Creador", condicionado en alguna medida por la época que corresponde a la publicación de cada formato. Pero en todos los casos, concluimos que el personaje representa a una mujer que se desmarca de los esquemas que la reducen al ámbito doméstico y la restringen a las etiquetas de cónyuge y progenitora.

Por último, en lo que se refiere a la transformación del personaje, podemos afirmar que Mildred Pierce evoluciona en todos los formatos analizados, aspecto que le aporta atractivo y también refuerza su vigencia a lo largo del tiempo (recordemos que la serie se estrena setenta años después de publicarse la novela). Nuestra protagonista crece en lo profesional y en lo personal, lo que podría expresarse en una serie de binomios, como sigue: de ama de casa a empresaria; de esposa complaciente a mujer separada por decisión propia en los difíciles años tras la depresión del 29; de mujer casada y madre con solo 17 años a divorciada y amante de un elegante burgués venido a menos; de empresaria hecha a sí misma, trabajadora y sensata, a mujer que despilfarra su dinero para comprar el cariño de su hija, hasta acercarse a la ruina; y por último, Mildred Pierce pasa de su obsesión por conseguir la aprobación de su hija, a liberarse de esta dependencia enfermiza, tras romper con Veda. Estos cambios se reflejan con una progresión muy rica en la serie, mientras que en el texto literario se abordan de forma un tanto brusca. La película, condicionada por su metraje, obvia parte de esta evolución y aporta a la historia un tono más dramático, especialmente en lo relativo al conflicto con Veda.

Observamos cómo Mildred Pierce consigue escapar de los moldes establecidos en esa sociedad americana y lucha por la emancipación de la mujer apropiando comportamientos que se escapan del entorno doméstico al que en un principio se le ha destinado. A través de la articulación de las tres narraciones, el personaje femenino trata de salir adelante cuestionando, como hemos visto en nuestra investigación, los conceptos de identidad, género y familia vigentes.

\section{Referencias Bibliográficas}

Atarama, Tomás; Castañeda, Lucía y Agapito, Claudia (2017). Los arquetipos como herramientas para la construcción de historias: análisis del mundo diegético de «Intensamente». Ámbitos. Revista Internacional de Comunicación, 36, 1-15. Disponible en: https://bit.ly/3b79F14

Cain, James M. (1980). Mildred Pierce. Barcelona: Ediciones del Cotal.

Caman Molero, Katherin y Atarama Rojas, Tomás (2015). Aportes del Derecho de la Comunicación a la ficción audiovisual: análisis del constitutivo esencial del mensaje cinematográfico a partir de la valoración del universo diegético de Toy Story. Derecom, 19, 183-203. Disponible en: http://www.derecom.com/derecom/

Chatman, Seymour (1990). Historia y discurso. La estructura narrativa en la novela y en el cine. Madrid: Taurus.

FormulaTV (13 abril 2011). 'The Kennedys', 'Mildred Pierce'y 'Being Human'se despiden con fuerza. Disponible en: https://bit. ly/2yizXPg (consultado el 5 de enero de 2021).

Galán, Elena (2006). Personajes, estereotipos y representaciones sociales. Una propuesta de estudio y análisis de la ficción televisiva. Eco-Pós, 9(1), 58-81. Disponible en: https://bit.ly/2VtFASJ.

González, Gabriela (21 febrero 2018). Estos datos muestran cómo Netflix tiene casi 3000 películas menos que en 2010 pero su catálogo de series se ha triplicado, Genbeta. Disponible en: https://bit.ly/2z3Md6P (consultado el 5 de enero de 2021).

Grossman, Julie (2009). Rethinking the Femme Fatale in Film Noir, Ready for Her Close-Up. Basingstoke: Palgrave MacMillan.

Herrero, Rocío (2010). La imagen de la mujer en la prensa entre 1910-1915 y 20000-2005: estudio comparado. Tesis doctoral. Madrid: Universidad Complutense de Madrid.

Igartua, Juan José (2008). Identificación con los personajes y persuasión incidental a través de la ficción cinematográfica. Escritos de Psicología, 2(1), 42-53. Disponible en: https://bit.ly/2xzArAL.

León del Río, Ma Belén (2009). Arquetipos e inconsciente colectivo en las artes plásticas a partir de la psicología de C. J. Jung. Arte, Individuo y Sociedad, 21, 37-49. doi: https://dx.doi.org/10.5209/ARIS. 
Lloyd, Justine y Johnson, Lesley (2003). The Three Faces of Eve: The Post-war Housewife, Melodrama, and Home 1. Feminist Media Studies, 3(1), 7-25. doi: https://dx.doi.org/10.1080/1468077032000080103.

Madden, David \& Mecholsky, Kristopher (2011). James M. Cain: Hard-Boiled Mythmaker. Plymouth: Scarecrow Press.

Maury, Cristelle (2017). Re-representing "The Great American Institution that Never Gets Mentioned on the Fourth of July". Transatlantica, 2, 1-14. Disponible en: https://bit.ly/3enH5dV.

McKee, Robert (2004). El guión. sustancia, escritura, estilo y principios de la escritura de guiones. Barcelona: Alba.

Navarrete-Galiano, Ramón (2012). Marlon Brando. La conceptualización de los personajes de Tennessee Williams. Escritura e imagen, 8, 9-21. https://bit.ly/2KpzI7V

Núñez, Antonio (2007). ¡Será mejor que lo cuentes!: los relatos como herramientas de comunicación. Madrid: Empresa activa.

Pérez, José Patricio (2016). Metodología de análisis del personaje cinematográfico: Una propuesta desde la narrativa fílmica. Razón y Palabra, 20(4-95), 534-552. Disponible en: https://bit.ly/3eqmOUT.

Prisa (19 septiembre 2011). Los Emmy premian las series de Canal+. Disponible en: https://bit.ly/3clIW13 (consultado el 10 de abril de 2020).

Rodríguez, Ma Elena (2007). Teorías sobre adaptación cinematográfica. Casa del Tiempo, 11, 82-91. Disponible en: https://bit. ly/2VyEZiP

Seger, Linda (2000). Cómo crear personajes inolvidables. Barcelona: Paidós.

Truby, John (2009). Anatomía del guión. El arte de narrar en 22 pasos. Barcelona: Alba.

Zamarripa, Adán (2006). Linda Seger: La psicología en la práctica del guionista. Revista Digital Universitaria, 7(9), 1-9. Disponible en: https://bit.ly/2RFd9jU 